\title{
Vitamin D Deficiency in Critically III Children
}

AUTHORS: Kate Madden, MD, a,b Henry A. Feldman, PhD, c,d,e Ellen M. Smith, BS, a Catherine M. Gordon, MD, MSc, c,e,f Shannon M. Keisling, BA, ${ }^{a}$ Ryan M. Sullivan, RN, ${ }^{\text {a Bruce W. }}$ Hollis, PhD, ${ }^{\circ}$ Anna A. Agan, BA, a and Adrienne G. Randolph, $\mathrm{MD}, \mathrm{MSc}^{\mathrm{a}, \mathrm{b}}$

aDivision of Critical Care Medicine, Department of Anesthesia, Perioperative and Pain Medicine, 'Division of Endocrinology, ${ }^{d}$ Clinical Research Program, and ${ }^{f}$ Division of Adolescent and Young Adult Medicine, Department of Pediatrics, Children's Hospital Boston, Boston, Massachusetts; Departments of ${ }^{b}$ Anaesthesia and ePediatrics, Harvard Medical School, Boston, Massachusetts; and ${ }^{~ D D e p a r t m e n t}$ of Pediatrics, Medical University of South Carolina, Charleston, South Carolina

\section{KEY WORDS}

critical care, vitamin D, septic shock

\section{ABBREVIATIONS}

25(OH)D—25-hydroxy vitamin D

$\mathrm{Cl}$-confidence interval

CV-SOFA-Sequential Organ Failure Assessment cardiovascular $\mathrm{IQR}$-interquartile range

LRTI-lower respiratory tract infection

OR一odds ratio

PRISM-III—Pediatric Risk of Mortality III

Drs Madden and Randolph participated in protocol conception and design, obtaining funding, subject enrollment, data collection, management analysis and interpretation, and manuscript preparation. Drs Feldman and Gordon participated in the study design, data analysis and interpretation, and critical revision of the article. Ms Smith, Ms Agan, Ms Keisling, and Mr Sullivan participated in the acquisition of data, data management, subject enrollment, laboratory sample management, data analysis, and manuscript revision. Dr Hollis participated in the study design and sample analysis and critically revised the manuscript.

www.pediatrics.org/cgi/doi/10.1542/peds.2011-3328

doi:10.1542/peds.2011-3328

Accepted for publication May 30, 2012

Address correspondence to Kate Madden, MD, Children's Hospital Boston, Division of Critical Care Medicine, Bader 634, 300 Longwood Ave, Boston, MA 02115. E-mail: kate.madden@childrens. harvard.edu

PEDIATRICS (ISSN Numbers: Print, 0031-4005; Online, 1098-4275). Copyright (C) 2012 by the American Academy of Pediatrics

(Continued on last page)
WHAT'S KNOWN ON THIS SUBJECT: Vitamin D is essential for bone health and for cardiovascular and immune function. In critically ill adults, vitamin D deficiency is common and associated with sepsis and with higher critical illness severity. The influence on pediatric critical illness is unclear.

WHAT THIS STUDY ADDS: We found a high prevalence of vitamin D deficiency in critically ill children, which was associated with higher critical illness severity. Vitamin D deficiency was less common in younger patients, in non-Hispanic white patients, in patients admitted over the summer, and in children taking supplemental vitamin D, with increasing amounts being more protective.

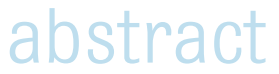

OBJECTIVE: Vitamin D influences cardiovascular and immune function. We aimed to establish the prevalence of vitamin $D$ deficiency in critically ill children and identify factors influencing admission 25hydroxy vitamin $\mathrm{D}(25(\mathrm{OH}) \mathrm{D})$ levels. We hypothesized that levels would be lower with increased illness severity and in children with serious infections.

METHODS: Participants were 511 severely or critically ill children admitted to the PICU from November 2009 to November 2010. Blood was collected near PICU admission and analyzed for 25(OH)D concentration by using Diasorin radioimmunoassay.

RESULTS: We enrolled 511 of 818 (62.5\%) eligible children. The median $25(\mathrm{OH}) \mathrm{D}$ level was $22.5 \mathrm{ng} / \mathrm{mL}$; $40.1 \%$ were $25(\mathrm{OH}) \mathrm{D}$ deficient (level $<20$ $\mathrm{ng} / \mathrm{mL}$ ). In multivariate analysis, age and race were associated with $25(\mathrm{OH}) \mathrm{D}$ deficiency; summer season, vitamin $\mathrm{D}$ supplementation, and formula intake were protective; $25(\mathrm{OH}) \mathrm{D}$ levels were not lower in the 238 children (46.6\%) admitted with a life-threatening infection, unless they had septic shock ( $n=51,10.0 \%$ ) (median 25(OH)D level 19.2 $\mathrm{ng} / \mathrm{mL} ; P=.0008$ ). After adjusting for factors associated with deficiency, lower levels were associated with higher admission day illness severity (odds ratio 1.19 for a 1-quartile increase in Pediatric Risk of Mortality III score per $5 \mathrm{ng} / \mathrm{mL}$ decrease in $25(\mathrm{OH}) \mathrm{D}, 95 \%$ confidence interval 1.10-1.28; $P<.0001$ ).

CONCLUSIONS: We found a high rate of vitamin $D$ deficiency in critically ill children. Given the roles of vitamin D in bone development and immunity, we recommend screening of those critically ill children with risk factors for vitamin $D$ deficiency and implementation of effective repletion strategies. Pediatrics 2012;130:421-428 
Vitamin D is essential for bone health ${ }^{1-4}$ and optimal cardiovascular ${ }^{5-10}$ and innate immune ${ }^{11-15}$ function. Levels of 25-hydroxy vitamin D $(25(\mathrm{OH}) \mathrm{D})$ are most often used to assess adequacy of vitamin $D$ stores. Patients with levels $<20 \mathrm{ng} / \mathrm{mL}$ are commonly categorized as vitamin D deficient, 1,16,17 and treatment is initiated in children to prevent rickets. ${ }^{16}$ Influenced by decreased vitamin $D$ intake and decreased sun exposure, $>60 \%$ of US children have insufficient levels of 25(OH) D ( $<30 \mathrm{ng} /$ $\mathrm{mL}$ ), with $15 \%$ being deficient. ${ }^{16-19}$ The rising rate of vitamin D insufficiency and deficiency has alarmed some experts, ${ }^{4,16,18-20}$ although others have questioned the clinical importance of $25(\mathrm{OH}) \mathrm{D}$ insufficiency. ${ }^{21}$

The level of $25(\mathrm{OH}) \mathrm{D}$ needed for adequate immune and cardiovascular function is unclear. Vitamin $\mathrm{D}$ deficiency has been associated with increased viral respiratory infections ${ }^{22-26}$ and sepsis ${ }^{27-29}$ in children and adults. Supplementing Japanese schoolchildren with $1200 \mathrm{IU}$ of vitamin D over winter months decreased influenza infections. ${ }^{30}$ This could be because 25(OH)D influences production of cathelicidin hCAP-18, an anti-microbial peptide. ${ }^{14,31}$ Critically ill adult patients with sepsis have lower vitamin D levels, associated with lower cathelicidin levels. ${ }^{28}$

Vitamin D deficiency has been associated with higher levels of admission illness severity in adult ICU patients. ${ }^{32-34}$ Low 25(OH)D levels prehospitalization and at ICU admission have been associated with short- and long-term allcause mortality and bacteremia in critically ill adults. $27,34,35$ The prevalence of vitamin $D$ deficiency and its influence on critical illness severity in children is unknown. We aimed to establish the prevalence of vitamin $D$ deficiency in a cohort of critically ill children and identify factors influencing $25(\mathrm{OH}) \mathrm{D}$ levels on admission to the pediatric ICU. We hypothesized that children with lower 25(OH)D levels would have higher illness severity and that levels would be lowest in PICU patients admitted for a life-threatening infection.

\section{METHODS}

We screened all children admitted to the medical-surgical PICUs from November 9, 2009 to November 9, 2010. Eligibility criteria included the following: (1) age $<21$ years and (2) estimated PICU stay of $\geq 48$ hours (excluding short-term monitoring patients) or admission due to a probable infection. Patients admitted to the cardiac ICU were excluded because of high incidence of cardiac bypass, which can lower 25 (OH)D levels. ${ }^{36}$ The Children's Hospital Boston institutional review board approved the study. After obtaining informed consent, parents or guardians were interviewed about their child's racial and ethnic background, sun exposure, and intake of vitamin D-containing foods and supplements by using a questionnaire adapted from a previous vitamin D study. ${ }^{16}$ Dose of vitamin D supplements (ergocalciferol or cholecalciferol) was obtained from parent report. Formula intake in diet was dichotomized as yes-no to account for inconsistency in daily intake amount between patients.

Blood was obtained as close as possible to PICU admission either by drawing fresh blood or retrieving samples of leftover plasma refrigerated in the hospital laboratory. All plasma was stored refrigerated, frozen at $-80^{\circ} \mathrm{C}$ within 7 days, then shipped frozen in batch for analysis. A direct radioimmunoassay developed in the Hollis laboratory and manufactured by Diasorin Corporation (Stillwater, MN) was used to measure total circulating $25(\mathrm{OH}) \mathrm{D}$ and $1,25(\mathrm{OH})_{2} \mathrm{D}$ concentrations (interand intraassay coefficient of variation of $10 \%) .37$

Height was not routinely collected to calculate BMI, so probable obesity was defined as admission weight $>2$ SD above the 50th percentile for age. Severity of illness in the first 24 hours was measured by using the Pediatric Risk of Mortality III (PRISM III) score.38 Maximum level of vasopressor use during PICU stay was assessed by using the Sequential Organ Failure Assessment cardiovascular (CV-SOFA) score with 0-1: no vasopressors, 2: dopamine $<5 \mathrm{mcg} / \mathrm{kg} / \mathrm{min}$, 3: dopamine 5 to $15 \mathrm{mcg} / \mathrm{kg} / \mathrm{min}$ or norepinephrine/ epinephrine $<0.1 \mathrm{mcg} / \mathrm{kg} / \mathrm{min}$, and 4: dopamine $>15 \mathrm{mcg} / \mathrm{kg} / \mathrm{min}$ or norepinephrine/epinephrine $>0.1 \mathrm{mcg} /$ $\mathrm{kg} / \mathrm{min}^{39}$

To determine infection status on admission, patients who had any cultures or viral testing performed on the PICU admission day, or with a diagnosis of a confirmed or suspected infection within 7 days before PICU admission, were reviewed by a critical care physician. Confirmed infection was defined as having a (1) culture of a pathogenic bacteria from blood, cerebrospinal fluid, or lung plus receipt of antibiotics; (2) positive fungal culture plus antifungal treatment; or (3) viral pathogen detected. Suspected infection included all patients meeting systemic inflammatory response syndrome or community acquired pneumonia criteria with negative microbial testing who received a course of antibiotic treatment. Severe septic shock was defined as confirmed or suspected infection with vasopressor therapy (CV-SOFA score $\geq 3$ ) on PICU admission day. Levels of $25(\mathrm{OH}) \mathrm{D}$ were categorized as normal $(\geq 30 \mathrm{ng} / \mathrm{mL})$, insufficient $(<30 \mathrm{ng} / \mathrm{mL}),{ }^{26,28}$ and deficient $(<20$ $\mathrm{ng} / \mathrm{mL}$ ). ${ }^{17,40,41}$ Data were managed by using REDCap (Research Electronic Data Capture) tools hosted at Children's Hospital Boston. ${ }^{42}$

In the most critically ill children, it was not possible to obtain prospective consent before or at PICU admission, so an accurate measurement of the child's 
fluid status at the exact time when the blood was sampled during fluid resuscitation was determined not to be feasible. When we were not able to obtain consent at the time of ICU admission, previously obtained and stored excess laboratory samples were retrieved from the clinical laboratory. Therefore, in a post hoc analysis, we tested whether timing of the blood sample relative to PICU admission was related to $25(\mathrm{OH}) \mathrm{D}$ level. In a second post hoc analysis, we evaluated the influence of total fluid bolus volume within $\leq 12$ hours before PICU admission on $25(\mathrm{OH}) \mathrm{D}$ level in subjects admitted from the emergency department, operating room, or inpatient ward at our institution.

To allow for the skewed distribution of 25(OH)D levels, we used the Spearman correlation coefficient to assess the association of 25(OH)D with continuous variables, the Mann-Whitney test for dichotomous variables, and the KruskalWallis test for multicategory variables. Patient characteristics associated with 25 $(\mathrm{OH}) \mathrm{D}$ in univariate analysis $(P \leq .10)$ were included in the multivariable model. We used multiple logistic regression to assess the influence of these risk factors on vitamin $D$ deficiency, dichotomized at $<20 \mathrm{ng} / \mathrm{mL}$. To model quartiles of PRISMIII score and the 4-level CV-SOFA score during PICU stay, we used ordinal multinomial logistic regression. SAS was used for all computations (version 9.2, SAS Institute, Cary, NC).

\section{RESULTS}

We screened 2366 patients admitted to the PICU between November 9, 2009, and November 9, 2010, and enrolled 511/818 (62.5\%) eligible patients with a plasma specimen available close to PICU admission. Reasons for nonenrollment of eligible subjects included the following: (1) consent refusal (12.3\%), (2) unavailable parents or guardians (14.7\%), and (3) no acceptable plasma specimen available
(10.6\%). Nonenrolled eligible patients were less likely to be receiving mechanical ventilation than those enrolled (59/ 307 [19.2\%] vs 337/511 [66\%], $P<.0001)$. The baseline characteristics of the cohort are shown in Table 1. The median patient age was 5.3 years (interquartile range [IQR] 1.4-12.9 years). The median 25(OH)D level of enrolled patients was $22.5 \mathrm{ng} / \mathrm{mL}$ (IQR 16.4-31.3); $71.2 \%$ had 25 $(\mathrm{OH}) \mathrm{D}$ insufficiency $(<30 \mathrm{ng} / \mathrm{mL})$, and $40.1 \%$ were $25(\mathrm{OH}) \mathrm{D}$ deficient (10-19.9 $\mathrm{ng} / \mathrm{mL}$ in $33.1 \%$ and $<10 \mathrm{ng} / \mathrm{mL}$ in $7 \%$ ). Thirteen (2.5\%) patients died during hospitalization (12 died while in the PICU), with a median 25(OH)D level of $19.4 \mathrm{ng} / \mathrm{mL}$ (IQR 16.6-31.4).

Table 1 shows the results of the univariate analyses of baseline factors present before PICU admission and their association with admission $25(\mathrm{OH})$ D levels. Children who were previously healthy and older children had lower 25 $(\mathrm{OH}) \mathrm{D}$ levels. History of vitamin $\mathrm{D}$ supplementation, intake of enteral formula (which contained 30-134 IU vitamin D/ cup), and admission during summer were associated with higher $25(\mathrm{OH}) \mathrm{D}$ levels. We had reliable parental report on home dose in 48 of the 64 patients taking uni-vitamin $D$ supplements in which the mean daily intake was 1320 IU. Although many multivitamins contain the recommended daily allowance of vitamin D (400 IU), some contain 100 to 200 IU per tablet, preventing accurate determination of daily vitamin $\mathrm{D}$. The 29 children with probable obesity had lower 25(OH)D levels than the children with normal or low body weight for age (mean 17.7 vs $22.7 \mathrm{ng} / \mathrm{mL}, P=.009$ ). History of renal disease before PICU admission was not associated with 25(OH)D level; patients with an elevated creatinine level near PICU admission actually had higher $25(\mathrm{OH}) \mathrm{D}$ levels (median 24.6 vs $20 \mathrm{ng} / \mathrm{mL}, P<.0001$ ).

In the multivariate analysis of $25(\mathrm{OH}) \mathrm{D}$ deficiency (Table 3 , model 1), past medical history was aggregated into 4 categories based on results of the univariate analyses: previously healthy, oncologic disorder, seizure disorder, and other chronic conditions. These categories were not significantly associated with $25(\mathrm{OH}) \mathrm{D}$ deficiency $(P=.21)$. Independent factors associated with decreased risk of 25(OH)D deficiency were younger age, white race with nonHispanic ethnicity, summer season, vitamin D supplementation, and formula intake.

As shown in Table 2, median 25(OH)D levels were not associated with the underlying reason for PICU admission which included confirmed or suspected life-threatening infection, although 25(OH)D levels were markedly lower in the 51 patients with severe septic shock. Each subgroup of infection was added to the regression model for 25(OH)D deficiency, including viral respiratory and septic shock; none had a significant effect alone or in aggregate. The 94 subjects diagnosed with lower respiratory tract infection (LRTI) had the same median 25- $(\mathrm{OH}) \mathrm{D}$ level $(22.5 \mathrm{ng} / \mathrm{mL})$ as those without, and addition of LRTI to the regression model of vitamin $D$ deficiency revealed no significant relationship $(P=.62)$.

Duration of mechanical ventilation during the PICU stay was not significantly associated with 25(OH)D ( $r=-0.1007, P=.10)$. The median PRISM-III raw score on admission day was 5 (IQR 0-11.5), and it was inversely correlated with $25(\mathrm{OH}) \mathrm{D}$ level $(r=-0.23, P<.0001$; see Fig $1 \mathrm{~A})$. A multinomial logistic regression model was created with PRISM-III quartiles as the outcome, adjusted for factors known previous to PICU admission associated with $25(\mathrm{OH}) \mathrm{D}$ admission levels. As shown in Table 3 (model 2), lower admission 25(OH)D was inversely associated with PRISM-III, with a $5 \mathrm{ng} / \mathrm{mL}$ decrease corresponding to a 1.19-fold increase in a patient's odds of belonging to the next higher PRISM-III quartile 
TABLE 1 Demographic and Other Characteristics of the Subjects Known Previous to PICU Admission and Association With 25(OH)D Levels

\begin{tabular}{|c|c|c|c|}
\hline Characteristic & $N(\%)$ & $25(\mathrm{OH}) \mathrm{D}, \mathrm{ng} / \mathrm{mL}^{\mathrm{a}}$ & $P$ Value $^{\mathrm{b}}$ \\
\hline Total sample & $511(100)$ & $22.5(16.4-31.3)$ & \\
\hline \multicolumn{4}{|l|}{ Gender } \\
\hline Female & $251(49.1)$ & $23.0(16.7-30.8)$ & \multirow[t]{2}{*}{.68} \\
\hline Male & $260(50.9)$ & $21.6(16.0-31.7)$ & \\
\hline \multicolumn{4}{|l|}{ Age, y } \\
\hline$<1$ & $98(19.2)$ & $26.6(16.7-37.0)$ & \multirow[t]{5}{*}{$<.0001^{\mathrm{c}}$} \\
\hline $1-4$ & $149(29.2)$ & $24.3(19.4-31.8)$ & \\
\hline $5-12$ & $137(26.8)$ & $20.6(14.2-29.6)$ & \\
\hline $13-17$ & $101(19.8)$ & $18.7(13.7-26.6)$ & \\
\hline $18-21$ & $26(5.1)$ & $24.8(19.4-27.5)$ & \\
\hline \multicolumn{4}{|l|}{ Race } \\
\hline White non-Hispanic & $321(62.8)$ & $23.2(16.9-31.5)$ & \multirow[t]{4}{*}{$.04^{\mathrm{d}}$} \\
\hline White Hispanic & $55(10.8)$ & $19.1(13.7-29.6)$ & \\
\hline Black & $67(13.1)$ & $20.8(13.7-29.8)$ & \\
\hline Other & $68(13.3)$ & $23.5(17.7-32.4)$ & \\
\hline \multicolumn{4}{|l|}{ Insurance } \\
\hline Private & $210(41.1)$ & $21.3(15.3-28.9)$ & \multirow[t]{2}{*}{.01} \\
\hline Government & $300(58.7)$ & $24.2(17.3-32.4)$ & \\
\hline \multicolumn{4}{|l|}{ Season } \\
\hline Fall or winter & $296(57.9)$ & $21.1(15.4-28.9)$ & \multirow[t]{3}{*}{$<.0001$} \\
\hline Spring & $127(24.9)$ & $22.4(15.6-30.3)$ & \\
\hline Summer & $88(17.2)$ & $29.9(20.6-41.8)$ & \\
\hline \multicolumn{4}{|l|}{ Supplements } \\
\hline Vitamin D or multivitamin & $182(35.6)$ & $25.4(17.6-35.9)$ & \multirow[t]{3}{*}{$<.0001$} \\
\hline Both & $31(6.1)$ & $31.1(24.7-41.8)$ & \\
\hline None & $298(58.3)$ & $20.4(14.8-27.7)$ & \\
\hline \multicolumn{4}{|l|}{ Enteral formula } \\
\hline Any & $208(40.7)$ & $27.8(20.0-38.0)$ & \multirow[t]{2}{*}{$<.0001$} \\
\hline None & $303(59.3)$ & $19.9(13.8-27.1)$ & \\
\hline \multicolumn{4}{|l|}{ Underlying chronic conditions } \\
\hline Any & $421(82.4)$ & $23.4(17.1-31.6)$ & \multirow[t]{2}{*}{.009} \\
\hline None & $90(17.6)$ & $20.5(14.3-27.1)$ & \\
\hline \multicolumn{4}{|l|}{ Underlying chronic conditionse } \\
\hline Respiratory & $213(50.6)$ & $24.3(17.0-34.5)$ & .30 \\
\hline Asthma & $106(25.2)$ & $21.1(16.0-31.0)$ & .33 \\
\hline Neurologic & $200(47.5)$ & $25.3(17.7-35.2)$ & .03 \\
\hline Seizure & $107(25.4)$ & $26.6(19.3-39.2)$ & .001 \\
\hline Oncologic & $55(13.1)$ & $19.6(14.0-26.2)$ & .003 \\
\hline Immunodeficiency & $31(7.4)$ & $24.3(19.0-31.1)$ & .64 \\
\hline Renal & $22(5.2)$ & $23.0(11.7-29.7)$ & .44 \\
\hline Gastrointestinal & $44(10.5)$ & $22.5(16.7-32.5)$ & .98 \\
\hline Nutritional & $49(11.6)$ & $29.8(20.0-33.0)$ & .05 \\
\hline Endocrine & $42(10.0)$ & $24.6(18.6-32.6)$ & .54 \\
\hline
\end{tabular}

a Median (quartile limits).

b Testing for association with serum 25(OH)D level by Mann-Whitney test (dichotomy) or Kruskal-Wallis test (multicategory characteristic)

c Spearman correlation between age and 25(OH)D level: $-0.18, P<.0001$

d "Other" category omitted from comparison.

e Compared with those with other chronic conditions

(95\% confidence interval [Cl] 1.10-1.28; $P<.0001)$. This was not explained by the cohort with septic shock, as addition of severe septic shock to this model altered the effect estimate minimally (odds ratio [OR] 1.18; $P<.0001$ ).

There were 134 patients (26.2\%) who received vasopressors (CV-SOFA $\geq 3$ ) during their PICU stay. Patients receiving vasopressors had lower 25(OH)D levels (median 19.8 vs $24.3 \mathrm{ng} / \mathrm{mL}, P<.0001$ ). Increasing vasopressor use (CV-SOFA score) was correlated with decreasing 25(OH)D levels ( $r=-.19, P<.0001$; Fig 1B). In the multinomial logistic regression model (Table 3, model 3), lower admission 25(OH)D levels were associated with higher CV-SOFA scores, a $5 \mathrm{ng} / \mathrm{mL}$ decrease corresponding to a 1.13-fold increase in odds of belonging to the next higher category of CV-SOFA score $(95 \% \mathrm{Cl}$ $1.01-1.27 ; P=.03)$. This effect remained after adjusting for severe septic shock (OR 1.16, 95\% Cl 1.02-1.31; $P=.02$ ).

The median timing of the first vitamin $D$ sampling was 0.6 hours after PICU admission (IQQR -5.3 to 9.7 hours). Timing of sampling was weakly inversely correlated with 25(OH)D level, $r=-.12, P=.009$. Fluid bolus data were available on $374 / 511$ patients $(73.1 \%)$ who were transferred from the inpatient ward, operating room, or the emergency department at our hospital. The median fluid bolus before PICU admission was $22.2 \mathrm{~mL} / \mathrm{kg}$, which had a weak inverse correlation with 25 $(\mathrm{OH}) \mathrm{D}$ level $(r=-.12, P=.01) .{ }^{43}$ Inclusion of the fluid resuscitation data did not markedly influence the association between any of the risk factors for vitamin D deficiency on PICU admission; all remained significant. Inclusion of fluid resuscitation volume into the model for predicting PRISM-III score showed that although increased fluid bolus amounts were associated with rising admission illness severity (OR 1.11, 95\% Cl 1.07-1.16, $P<.0001)$, 25(OH)D levels remained inversely associated with PRISM-III (OR 1.10, $95 \% \mathrm{Cl} 1.01-1.20, P=.03$ ). Fluid bolus volume before PICU admission was not a significant predictor of maximal $\mathrm{CV}$ SOFA score during the PICU stay (OR $1.04,95 \% \mathrm{Cl} 0.99-1.09, P=.11$ ) and was not tested as a potential confounder.

A post hoc comparison of $1,25(\mathrm{OH}) 2 \mathrm{D}$ levels between 17 cases with CV-SOFA $\geq 3$ to 18 children with CV-SOFA = 0 revealed a strong positive correlation between 25(OH)D and 1,25(OH)D levels, $r=.60, P<.0001$ with no respective differences in median 1,25(OH)2D levels (31.4 vs $45.1 \mathrm{pg} / \mathrm{mL}, P=.29$ ). Ionized calcium was measured on 245 subjects at admission, and was modestly correlated with $25(\mathrm{OH}) \mathrm{D}, r=.22, P=.0006$. However, only 30 patients had clinically low ionized calcium, and their $25(\mathrm{OH}) \mathrm{D}$ 
TABLE 2 Association of 25(OH)D Levels With Reason for PICU Admission and Admission to the PICU for a Life-Threatening Confirmed or Suspected Infection

\begin{tabular}{|c|c|c|c|}
\hline Characteristic & $N(\%)$ & $25(\mathrm{OH}) \mathrm{D}, \mathrm{ng} / \mathrm{mL}^{\mathrm{a}}$ & $P$ Value $^{\mathrm{b}}$ \\
\hline \multicolumn{4}{|l|}{ Reasons for PICU admission } \\
\hline Planned surgical & $115(22.6)$ & $22.9(17.3-31.4)$ & .40 \\
\hline Orthopedic & $43(8.4)$ & $19.4(14.4-29.6)$ & .12 \\
\hline Neurosurgical & $18(3.5)$ & $24.9(17.3-31.9)$ & .65 \\
\hline General surgery & $20(3.9)$ & $19.5(17.2-26.4)$ & .49 \\
\hline Other & $97(19.0)$ & $24.4(17.7-31.6)$ & .34 \\
\hline Emergent & $23(4.5)$ & $20.5(13.6-31.9)$ & .54 \\
\hline Trauma & $11(2.2)$ & $27.2(14.6-39.4)$ & .42 \\
\hline Status epilepticus/neurologic monitoring & $87(17.0)$ & $26.1(18.1-32.6)$ & .05 \\
\hline Electrolyte disturbance/diabetic ketoacidosis & $31(6.1)$ & $19.9(12.0-33.3)$ & .57 \\
\hline Asthma exacerbation & $44(8.6)$ & $22.3(18.1-30.0)$ & .51 \\
\hline Respiratory failure & $117(22.9)$ & $22.7(17.0-31.2)$ & .87 \\
\hline \multicolumn{4}{|l|}{ Infection on PICU admission } \\
\hline Any confirmed or suspected infectionc & $238(46.6)$ & $21.9(15.8-30.1)$ & .19 \\
\hline Positive viral test ${ }^{d}$ & $47(9.2)$ & $23.9(14.8-33.0)$ & .72 \\
\hline Positive bacterial teste & $97(19.0)$ & $20.0(15.3-31.9)$ & .28 \\
\hline No microbiologic confirmation & $94(18.4)$ & $21.8(16.1-29.0)$ & .40 \\
\hline Severe septic shock ${ }^{f}$ & $51(10.0)$ & $19.2(12.6-24.8)$ & .0008 \\
\hline
\end{tabular}

a Median (quartile limits).

b Testing for association with serum 25(OH) D level by Mann-Whitney test (dichotomy) or Kruskal-Wallis test (multicategory characteristic)

c Includes confirmed (viral, bacterial, fungal, multiple) or suspected infection; excludes confirmed but non-life-threating infection.

d Respiratory syncytial virus, influenza, parainfluenza, without confirmed bacterial infection.

e Sepsis, positive cerebrospinal fluid; includes fungal (5) and multiple (12)

${ }^{f}$ Cardiovascular sequential organ failure score $\geq 3$ plus confirmed or suspected infection.
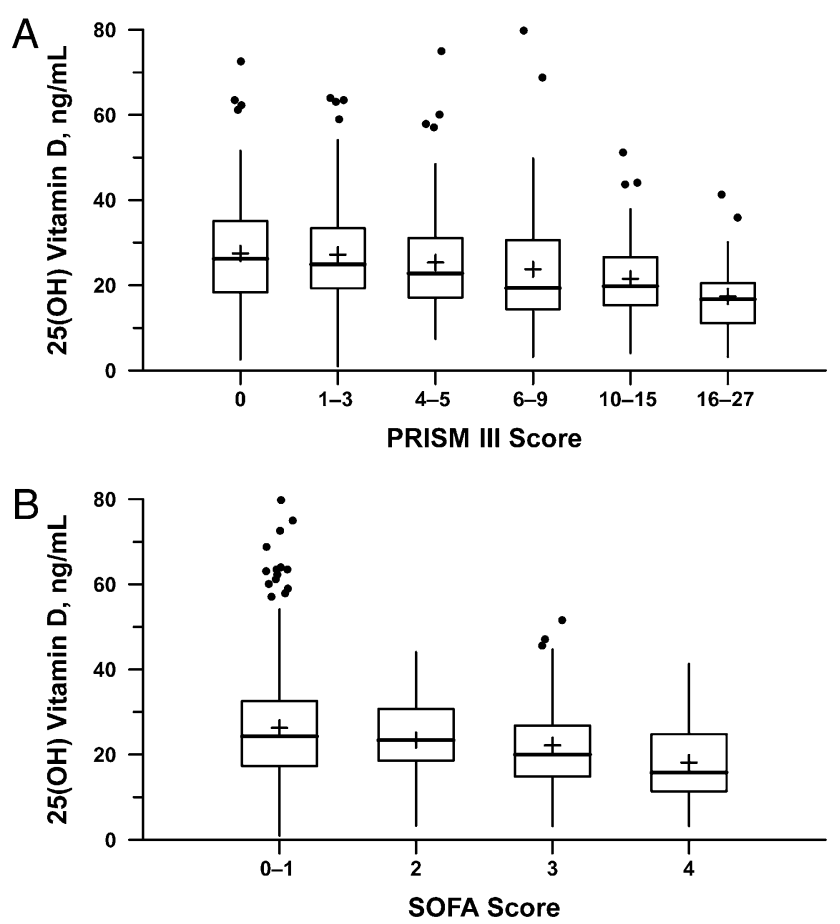

FIGURE 1

Correlation between $25(\mathrm{OH})$ vitamin D level and illness severity. A, 25(OH)D level is inversely correlated with PRISM-III score on PICU admission day. B, 25(OH)D level is inversely correlated with maximum cardiovascular SOFA (CV-SOFA) during ICU stay. The CV-SOFA score is calculated as follows: $0-1=$ no vasopressor requirement; $2=$ dopamine $\leq 5 \mathrm{mcg} / \mathrm{kg} / \mathrm{min} ; 3=$ dopamine $>5 \mathrm{mcg} / \mathrm{kg} / \mathrm{min}$ or epinephrine/norepinephrine $\leq 0.1 ; 4=$ dopamine $>15 \mathrm{mcg} / \mathrm{kg} / \mathrm{min}$ or epinephrine/norepinephrine $>0.1$. levels were similar to the 215 patients with normal levels (median 22.7 vs $24.5 \mathrm{ng} / \mathrm{mL}$, respectively, $P=.47$ ); the addition of this group had no effect on the regression models for PRISM-III or CV-SOFA scores.

\section{DISCUSSION}

We identified a high prevalence of vitamin $D$ deficiency and insufficiency in critically ill children in this prospective cohort study. Previously healthy children had lower 25(OH)D levels than those with underlying chronic illnesses, probably because parents of chronically ill children were more likely to report supplementing their children with vitamin $D$ by using vitamins and/or enteral formula. Vitamin D supplementation before PICU admission was strongly protective against $25(\mathrm{OH}) \mathrm{D}$ deficiency. School-age children, those with darker skin, and children not receiving vitamin $D$ supplementation were more likely to have low $25(\mathrm{OH}) \mathrm{D}$ levels, especially during colder months when sun exposure was limited. These risk factors for vitamin D deficiency we identified in these critically ill children have repeatedly been described as risk factors for vitamin $D$ deficiency in outpatients, 3,16,18,19,44,45 which supports our belief that the $25(\mathrm{OH}) \mathrm{D}$ levels drawn around PICU admission reflect preadmission status. As has been reported in critically ill adults, we found lower 25(OH)D levels associated with higher PICU admission day illness severity after adjusting for related preICU factors. ${ }^{27,34}$

The $40 \%$ prevalence of vitamin $D$ deficiency $(31 \%$ deficiency in infants and toddlers, $46 \%$ in school-age children, $57 \%$ in adolescents) in our cohort of critically ill children is higher than was reported in the healthy US pediatric population ( $9 \%$ in toddlers, ${ }^{18} 17 \%$ in school age, ${ }^{18}$ and $14 \%$ deficiency in adolescents ${ }^{17}$ ) and in studies of pediatric outpatients in Boston (12.1\% deficiency in infants and toddlers; $42 \%$ in healthy adolescents). ${ }^{19,35}$ Our high 
TABLE 3 Multiple Logistic Regression Models Assessing Joint Influence of Factors Associated With Vitamin D Deficiency, Influence of Vitamin D Levels and IIIness Severity (PRISM III Raw Score) After Adjusting for Model 1 Factors, and the Association Between Vitamin D Levels and Vasopressor Use (CV-SOFA Score), Adjusting for PRISM III and Model 1 Factors

\begin{tabular}{|c|c|c|c|c|}
\hline Predictor & Contrast & OR $(95 \% \mathrm{Cl})^{\mathrm{a}}$ & $p^{b}$ & $p^{c}$ \\
\hline \multicolumn{5}{|l|}{ 1. Vitamin $D<20 \mathrm{ng} / \mathrm{mL}$} \\
\hline Age & per $5 \mathrm{y}$ & $1.43(1.21-1.70)$ & $<.0001$ & \\
\hline Race & $\begin{array}{l}\text { Non-Hispanic white } \\
\text { versus other }\end{array}$ & $0.51(0.33-0.79)$ & .003 & \\
\hline Insurance & $\begin{array}{l}\text { Private versus } \\
\text { government }\end{array}$ & $0.84(0.54-1.30)$ & .43 & \\
\hline \multirow[t]{2}{*}{ Season } & $\begin{array}{l}\text { Summer versus } \\
\text { fall/winter }\end{array}$ & $0.27(0.14-0.51)$ & $<.0001$ & .0002 \\
\hline & $\begin{array}{l}\text { Summer versus } \\
\text { spring }\end{array}$ & $0.25(0.12-0.50)$ & .0001 & \\
\hline \multirow[t]{2}{*}{ Supplements } & $\begin{array}{l}\text { D or multivitamin } \\
\text { versus none }\end{array}$ & $0.54(0.35-0.84)$ & .006 & .001 \\
\hline & Both versus none & $0.20(0.06-0.62)$ & .006 & \\
\hline Formula & Any versus none & $0.38(0.24-0.61)$ & $<.0001$ & \\
\hline Previous medical history & - & - & - & .08 \\
\hline \multicolumn{5}{|c|}{ 2. Increasing PRISM III score (quartiles) } \\
\hline Serum 25(OH)D & $-5 \mathrm{ng} / \mathrm{mL}$ & $1.19(1.10-1.28)$ & $<.0001$ & \\
\hline Age & per 5 y & $1.20(1.05-1.38)$ & .008 & \\
\hline Race & $\begin{array}{l}\text { Non-Hispanic white } \\
\text { versus other }\end{array}$ & $0.95(0.68-1.32)$ & .75 & \\
\hline Season & - & - & - & .40 \\
\hline Supplements & - & - & - & 66 \\
\hline Formula & Any versus none & $1.56(1.08-2.27)$ & .02 & \\
\hline \multirow[t]{3}{*}{ Previous medical history } & Oncologic versus none & $2.64(1.42-4.91)$ & .002 & .01 \\
\hline & Oncologic versus seizure & $2.45(1.28-4.7)$ & .007 & \\
\hline & Oncologic versus other & $2.37(1.36-4.13)$ & .002 & \\
\hline \multicolumn{5}{|l|}{$\begin{array}{l}\text { 3. Increasing CV-SOFA score } \\
(0 / 1,2,3 \text {, or } 4)\end{array}$} \\
\hline Serum $25(\mathrm{OH}) \mathrm{D}$ & $-5 \mathrm{ng} / \mathrm{mL}$ & $1.13(1.01-1.27)$ & .03 & \\
\hline Age & per 5 y & $1.02(0.85-1.22)$ & .85 & \\
\hline Race & $\begin{array}{l}\text { Non-Hispanic white } \\
\text { versus other }\end{array}$ & $1.51(0.94-2.44)$ & .09 & \\
\hline Season & - & - & - & .97 \\
\hline Supplements & - & - & - & .86 \\
\hline Formula & Any versus none & $1.21(0.73-2.02)$ & .46 & \\
\hline \multirow[t]{3}{*}{ Previous medical history } & Oncological versus none & $0.22(0.09-0.52)$ & .0005 & .001 \\
\hline & Seizure versus none & $0.37(0.17-0.78)$ & .009 & \\
\hline & Other versus none & $0.36(0.20-0.65)$ & .0007 & \\
\hline PRISM III score & per 1 unit & $1.26(1.20-1.32)$ & $<.0001$ & \\
\hline
\end{tabular}

a $0 \mathrm{R}$ with $95 \% \mathrm{Cl}$, adjusted for all other predictors. For binary end point, $\mathrm{OR}$ is the multiplicative increase in odds of outcome associated with the indicated change in predictor. For ordinal end points, $\mathrm{OR}$ is the multiplicative increase in odds of outcome falling above any given division of categories associated with the indicated change in predictor.

b Testing hypothesis $\mathrm{OR}=1$. Any pairwise contrasts not listed were nonsignificant by Bonferroni criterion, $P>(.05 \div$ number of contrasts).

${ }^{\mathrm{c}}$ For multicategory predictors, testing equal likelihood of outcome in all categories.

prevalence of vitamin $D$ deficiency in critically ill children is more similar to that reported in adult ICU patients in France and Boston where $\geq 26 \%$ were reported as deficient. 27,46

In contrast to our expectations, we did not find critically ill children with confirmed or suspected infections to have lower 25(OH)D levels than other critically ill patient groups, with the exception of children presenting in severe septic shock. Studies have shown a relationship between vitamin $D$ levels and illness severity in infected children. Children with LRTI had a higher risk of hospital admission if their 25(OH) D level was in the severely deficient range. ${ }^{24}$ Children with acute LRTIs admitted to the PICU had lower 25(OH)D levels compared with children admitted to the ward. ${ }^{25}$ Unfortunately, we did not have a control group of children with infections who were not admitted to the PICU and were unable to test the relationship between hospitalization or PICU admission and 25(OH)D level in infected children.

We identified a relationship between illness severity, as defined by PRISM-III score on admission, and 25(OH)D level. The association between vitamin $\mathrm{D}$ level and both severity of illness and vasopressor use may be due to its role in innate immune function and inflammation, its role in calcium homeostasis, or influenced by fluid shifts and dilution. Because of interhospital transfers and poor documentation, we do not have reliable and complete data on fluid resuscitation before PICU admission for every subject. Even in those who were inhospital, where fluid bolus total amount was documented, it was usually not possible to accurately determine when the blood was sampled in relation to the fluid resuscitation. Although we were reassured that the inverse relationship between critical illness severity and 25 $(\mathrm{OH}) \mathrm{D}$ levels remained after adjusting for pre-PICU fluid bolus volume in patients where these data were available, we cannot accurately estimate the role of fluid shifts because this would require knowledge of 25(OH)D status in the preillness state.

Fluid resuscitation may explain the decreased vitamin D levels in children in septic shock. Studies in critically ill adults have shown an inverse relationship between outpatient vitamin D levels and illness severity and mortality in large adult cohorts. ${ }^{27}$ Vitamin D levels have been shown to be stable over the hospital course in patients with malaria ${ }^{47}$ and with acute myocardial infarction. ${ }^{48}$ However, they have also been shown to decrease by $40 \%$ in adults patients with an inflammatory response after knee surgery without significant fluid resuscitation and to remain decreased by $20 \%$ after hospitalization. ${ }^{49}$ Cardiac 
bypass has also been shown to markedly reduce $25(\mathrm{OH}) \mathrm{D}$ levels, ${ }^{36}$ which is why we excluded cardiac bypass patients and levels done during extracorporeal membrane oxygenation support. It remains unclear what portion of this relationship is due to fluid shifts, inflammation, or stores before illness onset.

Although we did not enroll $36.4 \%$ of the eligible patients, we believe that these nonenrolled patients were less likely to be critically ill because they were less likely than the enrolled group to have laboratory specimens drawn at admission and to receive mechanical ventilator support. We were also unable to thoroughly assess the Iongitudinal trend in $25(\mathrm{OH})$ D levels over the course of the PICU admission, and we believe the trend of $25(\mathrm{OH}) \mathrm{D}$ levels over

\section{REFERENCES}

1. Misra M, Pacaud D, Petryk A, CollettSolberg PF, Kappy M; Drug and Therapeutics Committee of the Lawson Wilkins Pediatric Endocrine Society. Vitamin D deficiency in children and its management: review of current knowledge and recommendations. Pediatrics. 2008;122 (2):398-417

2. Van den Berghe G, Van Roosbroeck D, Vanhove P, Wouters PJ, De Pourcq L, Bouillon R. Bone turnover in prolonged critical illness: effect of vitamin D. J Clin Endocrinol Metab. 2003;88(10):4623-4632

3. Wagner CL, Greer FR; American Academy of Pediatrics Section on Breastfeeding; American Academy of Pediatrics Committee on Nutrition. Prevention of rickets and vitamin D deficiency in infants, children, and adolescents. Pediatrics. 2008;122(5):1142-1152

4. Holick MF. Resurrection of vitamin D deficiency and rickets. J Clin Invest. 2006;116 (8) :2062-2072

5. Jablonski KL, Chonchol M, Pierce GL, Walker AE, Seals DR. 25-Hydroxyvitamin D deficiency is associated with inflammationlinked vascular endothelial dysfunction in middle-aged and older adults. Hypertension. 2011;57(1):63-69

6. Vaidya A, Forman JP, Hopkins PN, Seely EW, Williams JS. 25-Hydroxyvitamin D is associated with plasma renin activity and the pressor response to dietary sodium intake time in critically ill children is an important goal for future investigations.

\section{CONCLUSIONS}

We have identified a high prevalence of vitamin $D$ insufficiency, deficiency, and severe deficiency in critically ill children admitted to the PICU and an inverse association between $25(\mathrm{OH}) \mathrm{D}$ levels and illness severity on admission. Pre-PICU dietary intake of vitamin $D$ in the form of vitamins or formula protected against deficiency. We hypothesize that higher 25(OH)D levels may decrease the severity of critical illness brought on by an overwhelming insult such as infection or injury. Whether aggressive vitamin D supplementation in the early stages of critical illness improves clinical outcomes merits additional testing. Given

in Caucasians. J Renin Angiotensin Aldosterone Syst. 2011;12(3):311-319

7. Wang TJ, Pencina MJ, Booth SL, et al. Vitamin $D$ deficiency and risk of cardiovascular disease. Circulation. 2008;117(4):503-511

8. Judd SE, Tangpricha V. Vitamin D deficiency and risk for cardiovascular disease. Am J Med Sci. 2009;338(1):40-44

9. Kim DH, Sabour S, Sagar UN, Adams S, Whellan DJ. Prevalence of hypovitaminosis $D$ in cardiovascular diseases (from the National Health and Nutrition Examination Survey 2001 to 2004). Am J Cardiol. 2008; 102(11):1540-1544

10. Pfeifer M, Begerow B, Minne HW, Nachtigall $D$, Hansen C. Effects of a short-term vitamin $D(3)$ and calcium supplementation on blood pressure and parathyroid hormone levels in elderly women. J Clin Endocrinol Metab. 2001;86(4):1633-1637

11. Liu PT, Stenger S, Tang DH, Modlin RL. Cutting edge: vitamin D-mediated human antimicrobial activity against Mycobacterium tuberculosis is dependent on the induction of cathelicidin. J Immunol. 2007; 179(4):2060-2063

12. White JH. Vitamin D signaling, infectious diseases, and regulation of innate immunity. Infect Immun. 2008;76(9):38373843

13. Walker VP, Modlin RL. The vitamin D connection to pediatric infections and immune the high rate of vitamin $D$ deficiency in critically ill children and the essential role of vitamin $D$ in healthy bone development, we recommend screening critically ill children with risk factors for vitamin D deficiency and identifying effective repletion strategies.

\section{ACKNOWLEDGMENTS}

We thank the children and parents/ guardians who participated in this study. We also acknowledge the staff of the medical and surgical PICUs for their support. The Division of Critical Care and the Department of Anesthesia supported Drs Randolph and Madden throughout the project. The work of Ying Feng, MS, at the Clinical Research Program was helpful in the initial stages of the analysis. function. Pediatr Res. 2009;65(5 pt 2):106R113R

14. Liu PT, Stenger S, Li H, et al. Toll-like receptor triggering of a vitamin D-mediated human antimicrobial response. Science. 2006;311(5768):1770-1773

15. Enioutina EY, Bareyan D, Daynes RA. TLRinduced local metabolism of vitamin D3 plays an important role in the diversification of adaptive immune responses. J Immunol. 2009;182(7):4296-4305

16. Gordon CM, Feldman HA, Sinclair L, et al. Prevalence of vitamin D deficiency among healthy infants and toddlers. Arch Pediatr Adolesc Med. 2008;162(6):505-512

17. Saintonge S, Bang H, Gerber LM. Implications of a new definition of vitamin $D$ deficiency in a multiracial us adolescent population: the National Health and Nutrition Examination Survey III. Pediatrics. 2009;123(3):797-803

18. Mansbach JM, Ginde AA, Camargo CA Jr. Serum 25-hydroxyvitamin D levels among US children aged 1 to 11 years: do children need more vitamin D? Pediatrics. 2009;124 (5):1404-1410

19. Gordon CM, DePeter KC, Feldman HA, Grace E, Emans SJ. Prevalence of vitamin D deficiency among healthy adolescents. Arch Pediatr Adolesc Med. 2004;158(6):531-537

20. Merewood A, Mehta SD, Grossman X, et al. Widespread vitamin $D$ deficiency in urban 
Massachusetts newborns and their mothers. Pediatrics. 2010;125(4):640-647

21. Ross AC; Institute of Medicine. (U. S.). Committee to Review Dietary Reference Intakes for Vitamin $D$ and Calcium. Dietary Reference Intakes: Calcium Vitamin D. Washington, DC: National Academies Press; 2011

22. Savitha MR, Nandeeshwara SB, Pradeep Kumar MJ, ul-Haque F, Raju CK. Modifiable risk factors for acute lower respiratory tract infections. Indian J Pediatr. 2007;74 (5): 477-482

23. Ginde AA, Mansbach JM, Camargo CA Jr. Vitamin $D$ respiratory infections, and asthma Curr Allergy Asthma Rep. 2009;9(1):81-87

24. Wayse V, Yousafzai A, Mogale K, Filteau S. Association of subclinical vitamin $D$ deficiency with severe acute lower respiratory infection in Indian children under 5 y. Eur J Clin Nutr. 2004;58(4):563-567

25. McNally JD, Leis K, Matheson LA, Karuananyake C, Sankaran K, Rosenberg AM. Vitamin D deficiency in young children with severe acute lower respiratory infection. Pediatr Pulmonol. 2009;44(10):981-988

26. Ginde AA, Mansbach JM, Camargo CA Jr. Association between serum 25-hydroxyvitamin D level and upper respiratory tract infection in the Third National Health and Nutrition Examination Survey. Arch Intern Med. 2009; 169(4):384-390

27. Braun A, Chang D, Mahadevappa K, et al. Association of low serum 25-hydroxyvitamin D levels and mortality in the critically ill. Crit Care Med. 2011;39(4):671-677

28. Jeng L, Yamshchikov AV, Judd SE, et al Alterations in vitamin D status and antimicrobial peptide levels in patients in the intensive care unit with sepsis. J Trans/ Med. 2009;7:28

29. Ginde AA, Camargo CA Jr, Shapiro NI. Vitamin D insufficiency and sepsis severity in emergency department patients with suspected infection Acad Emerg Med. 2011;18(5):551-554

30. Urashima M, Segawa T, Okazaki M, Kurihara M, Wada $Y$, Ida H. Randomized trial of vitamin $D$ supplementation to prevent seasonal influenza A in schoolchildren. Am J Clin Nutr. 2010;91(5):1255-1260
31. Gombart AF, Borregaard N, Koeffler HP Human cathelicidin antimicrobial peptide (CAMP) gene is a direct target of the vitamin $D$ receptor and is strongly up-regulated in myeloid cells by 1,25-dihydroxyvitamin D3. FASEB J. 2005;19(9):1067-1077

32. McKinney JD, Bailey BA, Garrett LH, Peiris P Manning T, Peiris AN. Relationship between vitamin D status and ICU outcomes in veterans. J Am Med Dir Assoc. 2011;12(3):208211

33. Lee P, Eisman JA, Center JR. Vitamin D deficiency in critically ill patients. $N$ Engl $J$ Med. 2009:360(18):1912-1914

34. Braun AB, Gibbons FK, Litonjua AA, Giovannucc E, Christopher KB. Low serum 25-hydroxyvitamin $D$ at critical care initiation is associated with increased mortality. Crit Care Med. 2012:40(1):63-72

35. Braun A, Chang D, Mahadevappa K, et al Association of low serum 25-hydroxyvitamin D levels and mortality in the critically ill. Crit Care Med. 2011;39(4):671-677

36. Krishnan A, Ochola J, Mundy J, et al. Acute fluid shifts influence the assessment of serum vitamin $D$ status in critically ill patients. Crit Care. 2010;14(6):R216

37. Hollis BW, Johnson D, Hulsey TC, Ebeling M, Wagner CL. Vitamin D supplementation during pregnancy: double-blind, randomized clinical trial of safety and effectiveness. J Bone Miner Res. 2011;26(10): 2341-2357

38. Pollack MM, Patel KM, Ruttimann UE PRISM III: an updated Pediatric Risk of Mortality score. Crit Care Med. 1996;24(5): 743-752

39. Vincent JL, de Mendonça A, Cantraine F, et al. Use of the SOFA score to assess the incidence of organ dysfunction/failure in intensive care units: results of a multicenter, prospective study. Working group on "sepsis-related problems" of the European Society of Intensive Care Medicine. Crit Care Med. 1998;26(11):17931800

40. Hollis BW. Circulating 25-hydroxyvitamin D levels indicative of vitamin D sufficiency: implications for establishing a new effective dietary intake recommendation for vitamin D. J Nutr. 2005;135(2):317-322

41. Ross AC, Manson JE, Abrams SA, et al. The 2011 report on dietary reference intakes for calcium and vitamin $D$ from the Institute of Medicine: what clinicians need to know. J Clin Endocrinol Metab. 2011:96(1): 53-58

42. Harris PA, Taylor R, Thielke R, Payne J, Gonzalez N, Conde JG. Research electronic data capture (REDCap) — a metadata-driven methodology and workflow process for providing translational research informatics support. J Biomed Inform. 2009;42(2): 377-381

43. Weinberg SL, Abramowitz SK. Statistics Using SPSS: An Integrative Approach. 2nd ed. New York, NY: Cambridge University Press; 2008

44. Siddiqui TS, Rai MI. Presentation and predisposing factors of nutritional rickets in children of Hazara Division. J Ayub Med Coll Abbottabad. 2005:17(3):29-32

45. Huh SY, Gordon CM. Vitamin D deficiency in children and adolescents: epidemiology, impact and treatment. Rev Endocr Metab Disord. 2008;9(2):161-170

46. Lucidarme 0, Messai E, Mazzoni T, Arcade M, du Cheyron D. Incidence and risk factors of vitamin $\mathrm{D}$ deficiency in critically ill patients: results from a prospective observational study. Intensive Care Med. 2010;36(9):16091611

47. Newens K, Filteau S, Tomkins A. Plasma 25hydroxyvitamin $D$ does not vary over the course of a malarial infection. Trans $R$ Soc Trop Med Hyg. 2006;100(1):41-44

48. Barth JH, Field HP, Mather AN, Plein S. Serum 25 hydroxy-vitamin $D$ does not exhibit an acute phase reaction after acute myocardial infarction [published online ahead of print April 27, 2012]. Ann Clin Biochem. doi:10.1258/acb.2011.011195

49. Reid D, Toole BJ, Knox S, et al. The relation between acute changes in the systemic inflammatory response and plasma 25hydroxyvitamin $\mathrm{D}$ concentrations after elective knee arthroplasty. Am J Clin Nutr. 2011; 93(5):1006-1011

(Continued from first page)

FINANCIAL DISCLOSURE: Dr Hollis serves as a consultant for Diasorin Inc, Stillwater, MN; the other authors have indicated they have no financial relationships relevant to this article to disclose.

FUNDING: Supported by a grant from the Clinical Research Program (CRP) at Children's Hospital Boston. Dr Feldman was supported in part by Harvard Clinical and Translational Science Center, National Institutes of Health grant UL1 RR-025758. Dr Madden participated with support from Harvard Catalyst (National Institutes of Health award UL1 RR-025758 and financial contributions from Harvard University and its affiliated academic health care centers)

COMPANION PAPERS: Companions to this article can be found on pages 429 and 557, and online at www.pediatrics.org/cgi/doi/10.1542/peds.2011-3059 and www pediatrics.org/cgi/doi/10.1542/peds 